\title{
Effects of a Six-Week Daily Undulating Resistance Training Program on Anthropometric Characteristics, Biochemical Profile and Muscular Strength in an HIV-Seropositive Woman with Lipodystrophy: A Case Study
}

Hugo Ribeiro Zanetti ${ }^{1 *}$, Leonardo Roever ${ }^{2}$, Lucas Gonçalves da Cruz ${ }^{1}$, Camilo Luís Monteiro Lourenço, Fernando de Freitas Neves ${ }^{1}$, Mário Leon Silva-Vergara ${ }^{1}$ and Edmar Lacerda Mendes ${ }^{1}$

${ }^{1}$ Federal University of Triângulo Mineiro - Uberaba/MG, Brazil

${ }^{2}$ Department of Clinical Research - Federal University of Uberlândia - Uberlândia/MG, Brazil

\begin{abstract}
To investigate the effects of daily undulating periodization resistance training (DUPRT) program on anthropometric and biochemical profile and muscular strength in an HIV-infected woman with lipodystrophy. Case report: A 50 year old woman participated in a 6 week DUPRT program. Anthropometric and glycemic profile as well as blood lipid profile pre- and post-DUPRT.
\end{abstract}

Results: After six weeks, the participant showed increased body lean mass, circumference of arms, thighs and calf, HDL-c, and muscle strength. She also exhibited reduction in fat percentage and fat mass, circumference of neck, chest, waist, abdomen and hip, and levels of fasting glucose, triglyceride, total cholesterol, LDL-C and HBA1 ${ }_{\mathrm{C}}$.

Conclusion: Six weeks of DUPRT improved all evaluated profiles in an HIV-infected patient with lipodystrophy.

Keywords: Human immunodeficiency virus; Lipodystrophy syndrome; Resistance exercise; Non-linear training

\section{Introduction}

High active antiretroviral therapy (HAART) has modified the pathologic course of human immunodeficiency virus (HIV) infection by delaying virus replication and contributing to improved quality and expectancy of life in people living with HIV [1]. On the other hand, patients undergoing HAART experience side effects such nausea, vomiting, diarrhea, and headaches in the first months of HAART administration [2]. Moreover, long-term use of HAART may favor the development of liver cancer, kidney diseases and neurological disorders [3].

The most deleterious effects of HAART arise from protease inhibitor use [4] and include dyslipidemia, insulin resistance and lipodystrophy [5]. In turn, these alterations contribute to increased cardiovascular disease risk, the second leading cause of death in this population [6]. HIV-associated lipodystrophy syndrome (HIVLS) is characterized by lipoatrophy of the face and limbs and, lipohypertrophy in the abdomen, chest and neck [7]. While there are no defined criteria for the diagnosis of HIVLS, criteria such as patient's report, time of infection, time of HAART, dyslipidemia, low $\mathrm{CD}^{+}$cell count and age can be adopted [8].

Concurrent resistance and endurance training has been used successfully to decrease the side effects related to HAART use $[9,10]$. To the best of our knowledge, there is no clinical trial assessing the effects of daily undulating periodization resistance training (DUPRT) on HIVLS. Thus, the purpose of this study was to evaluate the effects of a 6-week DUPRT protocol on anthropometric, biochemical and immune profiles and muscular strength in a HIV-infected patient with lipodystrophy.

\section{Case Presentation}

A 50 year old Latin-American white woman was diagnosed with HIV infection contracted via a heterosexual relationship in 1995 and has received monthly treatment in a university hospital. In 1999, when her $\mathrm{CD} 4^{+}$count reduced to 446 cells $/ \mu \mathrm{L}$, she was started on treatment with lamivudine (3TC) $150 \mathrm{mg}$ and ziduvodina (AZT) $300 \mathrm{mg}$ twice a day. In 2012, efavirenz (EFZ) $600 \mathrm{mg}$ was added once a day. In October 2012, she reported a weight loss of $3.6 \mathrm{~kg}$ in two months and was clinically diagnosed with lipodystrophy. At the last medical visit her $\mathrm{CD}^{+}$and $\mathrm{CD} 8^{+}$cell counts were 586 and 1280 cells/ $\mu \mathrm{L}$ respectively and her viral load remained undetectable.

In September 2014, the patient signed an informed consent form to voluntarily participate in this study after guided ethical information was provided. This study was approved by the local Ethics Committee in Human Research (protocol number 994.745/2015) and registered in Brazilian clinical trials (protocol RBR-4rnq3v).

\section{Procedure}

At baseline and after 6 weeks of intervention, anthropometric measures, blood profiles and strength were assessed. All procedures were performed after a $48 \mathrm{~h}$ abstention from strenuous exercise and blood samples were collected after a $12 \mathrm{~h}$ fast.

\section{Anthropometric assessment}

Body mass $(\mathrm{BM})$ and height were measured using a mechanical

*Corresponding author: Hugo Ribeiro Zanetti, Federal University of Triângulo Mineiro, Avenida Tutunas, no. 490, Uberaba, MG, Brazil, Zip Code: 38061-500 Tel: +55 (34) 3318-5067; E-mail: hugo.zanetti@hotmail.com

Received May 27, 2016; Accepted June 08, 2016; Published June 15, 2016

Citation: Zanetti HR, Roever L, da Cruz LG, Lourenço CLM, de Freitas Neves F, et al. (2016) Effects of a Six-Week Daily Undulating Resistance Training Program on Anthropometric Characteristics, Biochemical Profile and Muscular Strength in an HIV-Seropositive Woman with Lipodystrophy: A Case Study. J AIDS Clin Res 7 588. doi:10.4172/2155-6113.1000588

Copyright: (c) 2016 Zanetti HR, et al. This is an open-access article distributed under the terms of the Creative Commons Attribution License, which permits unrestricted use, distribution, and reproduction in any medium, provided the original author and source are credited. 
Citation: Zanetti HR, Roever L, da Cruz LG, Lourenço CLM, de Freitas Neves F, et al. (2016) Effects of a Six-Week Daily Undulating Resistance Training Program on Anthropometric Characteristics, Biochemical Profile and Muscular Strength in an HIV-Seropositive Woman with Lipodystrophy: A Case Study. J AIDS Clin Res 7: 588. doi:10.4172/2155-6113.1000588

Page 2 of 4

scale and stadiometer, respectively (Filizola, Campo Grande/MS, Brazil). Body mass index (BMI) was calculated using Quetelet index (BMI=body mass $(\mathrm{kg}) /$ height $\left.^{2}(\mathrm{~m})\right)$. Circumference measures of the neck, chest, abdomen, hips, arms, thighs and calf were obtained using anthropometric tape (Sanny, São Bernardo do Campo/SP, Brazil).

A scientific skinfold caliper (Sanny', São Bernardo do Campo/SP, Brazil) was used to measure skinfolds at seven sites: the chest, triceps, subscapularis, midaxillary, suprailiac, abdominal and thigh. For greater reliability, triplicate measurements of each skinfold were obtained and the mean of the three measures was calculated. Pollock's sevensite skinfold equation was used to calculate body density [11], whereas Siri equation was used to predict body fat percentage (BF\%). Florindo equation [12] was used to predict central subcutaneous fat (CSF), peripheral subcutaneous fat (PSF) and total subcutaneous fat (TSF).

\section{Biochemical assessment}

Blood samples were collected to asses fasting glucose (FG), glycosylated hemoglobin $\left(\mathrm{HBA}_{1 \mathrm{C}}\right)$, triglyceride $(\mathrm{TG})$, total cholesterol (TC), high density lipoprotein (HDL-c) and low density lipoprotein (LDL-c) levels. All procedures were performed in a university hospital and the patient was instructed to fast for 12-14 $\mathrm{h}$ and to abstain from alcohol for $72 \mathrm{~h}$. After collection, blood samples were immediately centrifuged at $3500 \mathrm{rpm}$ for $5 \mathrm{~min}$. Biochemical profiles were analyzed by enzymatic colorimetric methods using specific commercially available kits on a CIBA CORNING 550 Express Analyzer (Bayer, Minnesota, USA).

\section{Muscle strength assessment}

The patient was subjected to one repetition maximum (1RM) test [13] for the evaluation of muscle strength in all proposed exercises. Two tests were conducted per day, one for upper limbs and one for lower limbs.

\section{Exercise Program}

After a two-week familiarization period, which occurred with $12-15$ repetitions (two sets), and load $<60 \%$ of $1 \mathrm{RM}$, the patient was assessed per a 6 week DUPRT protocol as shown in Table 1.

\section{Results}

The patient's anthropometric measures and body composition characteristics are shown in Table 2. The patient's BMI decreased by $2.44 \%$ due to the loss of $0.9 \mathrm{~kg}$ of body mass. Reduction was observed in the circumference of neck, chest, waist abdomen and hip and increase was observed in the circumference of arms, thighs and calf. Positive changes were observed in her body composition after six weeks of intervention: TSF and CSF levels were reduced by $18 \mathrm{~mm}$ whereas PSF was unchanged. Percentage of body fat decreased to $33.95 \%$ due to the loss of $2.64 \mathrm{~kg}$ of fat. Her lean body mass increased by $1.54 \mathrm{~kg}$.

The patient's biochemical results showed a reduction in FG

\begin{tabular}{|c|c|c|c|}
\hline EXERCISE & MONDAYA & WEDNESDAYB & FRIDAYC $^{\text {C }}$ \\
\hline Squat & $3 \times 4-6 \mathrm{RM}$ & $3 \times 15-20 \mathrm{RM}$ & $3 \times 8-12 \mathrm{RM}$ \\
\hline Bench Press & $3 \times 4-6 \mathrm{RM}$ & $3 \times 15-20 \mathrm{RM}$ & $3 \times 8-12 \mathrm{RM}$ \\
\hline Hamstring Curl & $3 \times 4-6 \mathrm{RM}$ & $3 \times 15-20 \mathrm{RM}$ & $3 \times 8-12 \mathrm{RM}$ \\
\hline Pulldown & $3 \times 4-6 \mathrm{RM}$ & $3 \times 15-20 \mathrm{RM}$ & $3 \times 8-12 \mathrm{RM}$ \\
\hline Calf Sitting & $3 \times 4-6 \mathrm{RM}$ & $3 \times 15-20 \mathrm{RM}$ & $3 \times 8-12 \mathrm{RM}$ \\
\hline Shoulder Press & $3 \times 4-6 \mathrm{RM}$ & $3 \times 15-20 \mathrm{RM}$ & $3 \times 8-12 \mathrm{RM}$ \\
\hline
\end{tabular}

RM: Repetition Maximum; a, b, ${ }^{c}$ Rest intervals (RI) between sets and exercises aRI=3'; 'RI=45"; 'RI=1'30"

Table 1: Daily undulating periodization program.

\begin{tabular}{|c|c|c|c|c|}
\hline Variable & Pre-test & Post-test & Change & Change (\%) \\
\hline Body mass $(\mathrm{kg})$ & 44.60 & 43.50 & -0.9 & -2.47 \\
\hline Body mass index $\left(\mathrm{kg} / \mathrm{m}^{2}\right)$ & 20.08 & 19.59 & -0.49 & -2.44 \\
\hline Circumference & & & & \\
\hline Neck $(\mathrm{cm})$ & 21 & 20.5 & -0.05 & -2.38 \\
\hline Chest $(\mathrm{cm})$ & 71 & 70.5 & -0.05 & -0.70 \\
\hline Waist $(\mathrm{cm})$ & 61 & 60.5 & -0.05 & -0.82 \\
\hline Abdomen $(\mathrm{cm})$ & 63.5 & 61.5 & -2.0 & -3.25 \\
\hline Hip $(\mathrm{cm})$ & 71 & 70 & -1.0 & -1.43 \\
\hline Right Arm $(\mathrm{cm})$ & 13 & 13.5 & +0.05 & +3.70 \\
\hline Left Arm $(\mathrm{cm})$ & 12.5 & 13 & +0.05 & +3.85 \\
\hline Right Thighs $(\mathrm{cm})$ & 36 & 38 & +2.0 & +5.26 \\
\hline Left Thighs $(\mathrm{cm})$ & 35.5 & 37.5 & +2.0 & +5.33 \\
\hline Right Calf $(\mathrm{cm})$ & 21 & 22 & +1.0 & +4.55 \\
\hline Left Calf $(\mathrm{cm})$ & 21 & 22 & +1.0 & +4.55 \\
\hline Waist-Hip Ratio $(\mathrm{cm})$ & 0,85 & 0,86 & +0.01 & +1.16 \\
\hline Body Composition & & & & \\
\hline TSF $(\mathrm{mm})$ & 74 & 56 & -18 & -24.32 \\
\hline CSF $(\mathrm{mm})$ & 60 & 42 & -18 & -30 \\
\hline PSF $(\mathrm{mm})$ & 14 & 14 & 0 & 0 \\
\hline Fat $(\%)$ & 21,78 & 16,26 & -5.52 & -33.95 \\
\hline Body Fat Mass $(\mathrm{kg})$ & 9.71 & 7.07 & -2.64 & -37.34 \\
\hline Lean Body Mass $(\mathrm{kg})$ & 34.88 & 36.42 & +1.54 & +4.23 \\
\hline Cen & & & \\
\hline
\end{tabular}

CM: Centimeters; $\mathrm{mm}$ : Millimeters; \%: Percentage; $\mathrm{kg}$ : kilograms; TSF Total Subcutaneous Fat; CSF: Central Subcutaneous Fat; PSF: Peripheral Subcutaneous Fat.

Table 2: Anthropometric variables in baseline and after six weeks of NLRT.

\begin{tabular}{|c|c|c|c|c|}
\hline Variable & Pre-test & Post-test & Change & Change (\%) \\
\hline Fasting Glucose (mg/dL) & 120 & 102.9 & -17.10 & -14.25 \\
\hline Triglycerides (mg/dL) & 185 & 180 & -5 & -2.70 \\
\hline Total Cholesterol (mg/dL) & 301.5 & 251.1 & -50.40 & -16.72 \\
\hline $\mathrm{HDL}(\mathrm{mg} / \mathrm{dL})$ & 45 & 56 & +11 & +24.44 \\
\hline $\mathrm{LDL}(\mathrm{mg} / \mathrm{dL})$ & 219.5 & 189.6 & -29.90 & -13.62 \\
\hline $\mathrm{HBA} 1_{\mathrm{C}}(\%)$ & 6.02 & 5.84 & -0.18 & -2.99 \\
\hline
\end{tabular}

HDL: High Density Lipoprotein; LDL: Low Density Lipoprotein; HBA1 : Glycosylated Hemoglobin

Table 3: Biochemical variables in baseline and after six weeks of NLRT.

\begin{tabular}{|c|c|c|c|c|}
\hline Strength measures & Pre-test & Post-test & Change & Change (\%) \\
\hline Squat $(\mathrm{kg})$ & 30 & 54 & +24 & 80.0 \\
\hline Bench press $(\mathrm{kg})$ & 22 & 36 & +14 & 63.6 \\
\hline Hamstring curl (kg) & 24 & 40 & +16 & 66.7 \\
\hline Pulldown $(\mathrm{kg})$ & 38 & 55 & +17 & 44.7 \\
\hline Calf sitting $(\mathrm{kg})$ & 40 & 90 & +50 & 125.0 \\
\hline Shoulder press $(\mathrm{kg})$ & 18 & 28 & +10 & 55.6 \\
\hline
\end{tabular}

kg: kilograms

Table 4: Muscle strength at baseline and at the end of six weeks of DUP intervention.

(14.25\%), TG (2.70\%), TC (16.72\%), LDL (16.72\%), and HBA $\mathrm{HC}_{1 \mathrm{C}}(2.99 \%)$ and an increase in HDL-c (24.44\%) as shown in Table 3.

The patient's muscle strength increased in squat (80\%), bench press (63.3\%), hamstring curl (66.7\%), pulldown (44.7\%), calf sitting (125\%) and shoulder press (55.6\%) as shown in Table 4.

\section{Discussion}

Our results show that a 6-week DUPRT program is effective in 
Citation: Zanetti HR, Roever L, da Cruz LG, Lourenço CLM, de Freitas Neves F, et al. (2016) Effects of a Six-Week Daily Undulating Resistance Training Program on Anthropometric Characteristics, Biochemical Profile and Muscular Strength in an HIV-Seropositive Woman with Lipodystrophy: A Case Study. J AIDS Clin Res 7: 588. doi:10.4172/2155-6113.1000588

Page 3 of 4

improving body composition, biochemical variables and muscle strength in a woman with HIV-associated lipodystrophy syndrome. Although previous studies have successfully used endurance and concurrent exercise programs [10], to the best of our knowledge, this is the first study to assess DUP in a patient with this disease.

Resistance exercise is the method of choice due to its effectiveness in promoting positive body fat changes (i.e. increase in lean body mass and decrease in fat body mass) [14]. Additionally, resistance training periodization is an important tool to individualize training and to maximize results when compared with non-periodized training [15]. Specifically, DUP yields better results when compared with other periodization approaches, primarily in muscle strength, endurance and increase in lean body mass [16-18].

Although no safe and effective therapy is available for treatment of HIVLS, some studies have shown positive results with growth hormone, testosterone, hypoglycemic therapies or statins $[19,20]$. Even though such therapies exhibit high efficiency with few side effects, they are not recommended due to their high cost. In contrast, our results show that a 6 week DUP program can be an effective low cost strategy to reduce HAART side effects.

Decreases were observed in the patient's neck $(2.3 \%)$, chest $(0.7 \%)$, waist $(0.8 \%)$, abdomen $(3.2 \%)$ and hip (1.4\%) circumference. HIVLS primarily affects these sites and they are considered cardiovascular risk factors [21]. In addition, a reduction in body fat mass $(2.64 \%)$ was observed. Increase in fat body mass is associated with higher levels of pro-inflammatory cytokines such as interleukin-1beta, interleukin-6, tumor necrosis factor-alpha and C-reactive protein, which contribute to cardiovascular diseases $[22,23]$. In addition, we found a reduction in TG (2.7\%), TC (16.7\%) and LDL (13.6\%) and increase in HDL (24.4\%) levels. These results are significant since HAART causes dyslipidemia for which statin administration may be required. Thus, in addition to assisting in body aesthetics, DUP may delay the development of cardiometabolic diseases and attenuate the severity of HAART side effects.

Another important finding was the increase in lean body mass (4.23\%). HIV-infected patients often experience a loss of skeletal muscle mass, resulting in low aerobic capacity and consequently low physical activity levels $[24,25]$. The rapid weight loss and muscle wasting contribute to sarcopenia [26]. Moreover, the reduction in FG (14.2\%), $\mathrm{HBA}_{1 \mathrm{C}}(2.99 \%)$ can be explained by the lean body mass increase, because glucose transporter protein (GLUT4) is closely related to the size of the muscle tissue [27].

Raso et al. [28] demonstrated that physically active HIV-positive patients can preserve aerobic capacity, despite not having a controlled routine. However, muscle strength cannot be sustained without a controlled routine. They showed that DUP resistance training presents higher gains in muscle strength, but our results demonstrated strength gain in all indicated exercises, ranging from $44.7 \%$ to $125 \%$ after a 6 week DUP program, which can contribute to daily life activities.

In conclusion, our present study revealed that DUPRT is an effective, efficient, low cost, non-pharmacological intervention for HIVassociated lipodystrophy. However, these findings can only be applied to this case. Further interventional studies are needed to confirm the effectiveness of DUP on anthropometric characteristics, biochemical profile and muscular strength in HIV-infected patients.

\section{Financial Support}

Fundação de Amparo à Pesquisa do Estado de Minas Gerais (grant no. APQ01729-14).

\section{References}

1. Barbaro $G$ (2006) Metabolic and cardiovascular complications of highly active antiretroviral therapy for HIV infection. Curr HIV Res 4: 79-85.

2. Jain RG, Furfine ES, Pedneault L, White AJ, Lenhard JM (2001) Metabolic complications associated with antiretroviral therapy. Antiviral Res 51: 151-177.

3. Hartmann M (2006) The side effects of antiretroviral therapy. Hautarzt 57: 969-974

4. Stein JH (2003) Dyslipidemia in the era of HIV protease inhibitors. Prog Cardiovasc Dis 45: 293-304.

5. Chanu B, Valensi P (2005) Lipid disorders in patients with HIV-induced diseases. Presse Med 34: 1087-1094

6. Barbaro G (2006) Highly active antiretroviral therapy-associated metabolic syndrome: Pathogenesis and cardiovascular risk. Am J Ther 13: 248-260.

7. Parakh A, Dubey AP, Kumar A, Maheshwari A (2009) Lipodystrophy and metabolic complications of highly active antiretroviral therapy. Indian J Pediatr 76: 1017-1021.

8. Carr A, Emery S, Law M, Puls R, Lundgren JD, et al. (2003) An objective case definition of lipodystrophy in HIV-infected adults: A case-control study. Lancet 361: 726-735

9. Hand GA, Phillips KD, Dudgeon WD, William Lyerly G, Larry Durstine J, et al. (2008) Moderate intensity exercise training reverses functional aerobic impairment in HIV-infected individuals. AIDS Care 20: 1066-1074.

10. Gomes Neto M, Ogalha C, Andrade AM, Brites C (2013) A systematic review of effects of concurrent strength and endurance training on the health-related quality of life and cardiopulmonary status in patients with HIVIAIDS. Biomed Res Int 2013: 1-8.

11. Jackson AS, Pollock ML, Ward A (1980) Generalized equations for predicting body density of women. Med Sci Sports Exerc 12: 175-181.

12. Florindo AA, Latorre Mdo R, Santos EC, Borelli A, Rocha Mde S, et al. (2004) Validation of methods for estimating HIVIAIDS patients' body fat. Rev Saude Publica 38: 643-649

13. Guaraldi G, Orlando G, Squillace N, De Santis G, Pedone A, et al. (2006) Multidisciplinary approach to the treatment of metabolic and morphologic alterations of HIV-related lipodystrophy. HIV Clin Trials 7: 97-106.

14. Roubenoff R, McDermott A, Weiss L, Suri J, Wood M, et al. (1999) Short-term progressive resistance training increases strength and lean body mass in adults infected with human immunodeficiency virus. AIDS 13: 231-239.

15. Rhea MR, Alderman BL (2004) A meta-analysis of periodized versus nonperiodized strength and power training programs. Res Q Exerc Sport 75: 413-422.

16. Manolov R, Jamieson M, Evans JJ, Sierra V (2015) Probability and visual aids for assessing intervention effectiveness in single-case designs: A field test Behav Modif 39: 691-720.

17. Rhea MR, Ball SD, Phillips WT, Burkett LN (2003) A comparison of linear and daily undulating periodized programs with equated volume and intensity for strength. J Strength Cond Res 16: 250-255

18. Rhea MR, Phillips WT, Burkett LN, Stone WJ, Ball SD, et al. (2002)A comparison of linear and daily undulating periodized programs with equated volume and intensity for local muscular endurance. J Strength Cond Res 17: 82-87.

19. Radermecker RP, Piérard GE, Scheen AJ (2007) Lipodystrophy reactions to insulin: effects of continuous insulin infusion and new insulin analogs. Am J Clin Dermatol 8: 21-28.

20. Burgess E, Wanke C (2005) Use of recombinant human growth hormone in HIVassociated lipodystrophy. Current Opinion in Infectious Diseases 18: 17-24.

21. Lake JE, Wohl D, Scherzer R, Grunfeld C, Tien PC, et al. (2011) Regional fat deposition and cardiovascular risk in HIV infection: The FRAM study. AIDS Care 23: 929-938.

22. Triant VA, Meigs JB, Grinspoon SK (2009) Association of C-reactive protein and HIV infection with acute myocardial infarction. J Acquir Immune Defic Syndr 51: 268-273.

23. Dagogo-Jack S (2008) HIV therapy and diabetes risk. Diabetes Care 31: 12671268.

24. Thibault R, Cano N, Pichard C (2011) Quantification of lean tissue losses during cancer and HIV infection/AIDS. Curr Opin Clin Nutr Metab Care 14: 261-267. 
Citation: Zanetti HR, Roever L, da Cruz LG, Lourenço CLM, de Freitas Neves F, et al. (2016) Effects of a Six-Week Daily Undulating Resistance Training Program on Anthropometric Characteristics, Biochemical Profile and Muscular Strength in an HIV-Seropositive Woman with Lipodystrophy: A Case Study. J AIDS Clin Res 7: 588. doi:10.4172/2155-6113.1000588

25. Tanaka LF, Latorre Mdo R, Silva AM, Konstantyner TC, Peres SV, et al. (2015) High prevalence of physical inactivity among adolescents living with HIV/Aids. Rev Paul Pediatr 33: 327-332.

26. Kietrys D, Galantino ML (2014) Can progressive resistive exercise improve weight, limb girth and strength of individuals with HIV disease? Phys Ther 94: 329-333.
27. Gaster M, Vach W, Beck-Nielsen H, Schroder HD (2002) GLUT4 expression at the plasma membrane is related to fibre volume in human skeletal muscle fibres. APMIS 110: 611-619.

28. Raso V, Shephard RJ, Casseb J, Duarte AJ, Silva PR, et al. (2013) Association between muscle strength and the cardiopulmonary status of individuals living with HIVIAIDS. Clinics (Sao Paulo) 68: 359-364. 